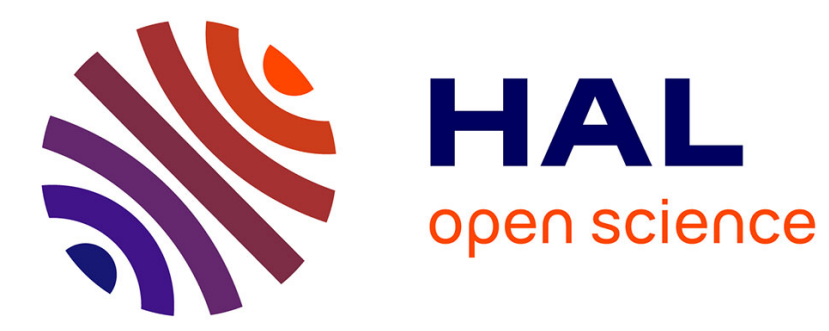

\title{
Seismic behavior \& risk assessment of an existing bridge considering soil-structure interaction using artificial neural networks
}

\author{
Mohammed Rachedi, Mohammed Matallah, Panagiotis Kotronis
}

\section{To cite this version:}

Mohammed Rachedi, Mohammed Matallah, Panagiotis Kotronis. Seismic behavior \& risk assessment of an existing bridge considering soil-structure interaction using artificial neural networks. Engineering Structures, 2021, 232, pp.111800. 10.1016/j.engstruct.2020.111800 . hal-03119427

\author{
HAL Id: hal-03119427 \\ https://hal.science/hal-03119427
}

Submitted on 2 May 2021

HAL is a multi-disciplinary open access archive for the deposit and dissemination of scientific research documents, whether they are published or not. The documents may come from teaching and research institutions in France or abroad, or from public or private research centers.
L'archive ouverte pluridisciplinaire HAL, est destinée au dépôt et à la diffusion de documents scientifiques de niveau recherche, publiés ou non, émanant des établissements d'enseignement et de recherche français ou étrangers, des laboratoires publics ou privés.

\section{(ㄷ)(1) $\$$}

Distributed under a Creative Commons Attribution - NonCommerciall 4.0 International 


\title{
Seismic behavior \& risk assessment of an existing bridge considering soil-structure interaction using artificial neural networks
}

\author{
Mohammed RACHEDI ${ }^{* 1}$, Mohammed MATALLAH ${ }^{1}$, and Panagiotis KOTRONIS ${ }^{2}$ \\ ${ }^{1}$ RISAM Research Laboratory, University of Tlemcen, Tlemcen, ALGERIA \\ ${ }^{2}$ Ecole Centrale de Nantes, Université de Nantes, CNRS, Institut de Recherche en Génie Civil et Mécanique (GeM)
}

\begin{abstract}
The Peak Ground Acceleration (PGA) is extensively used in earthquake engineering practice to describe the ground motion characteristics for establishing the seismic vulnerability curves. However, a single parameter is not enough to describe the seismic excitation and does not allow expressing the complex relationship between the structural damage and the ground movement. Motivated to overcome these shortcomings, several ANN-based models were proposed to predict the seismic structural damage using other parameters. Unfortunately, not all include soil structure interaction. This paper aims to explore the predictive power of an ANN-based approach to reproduce the nonlinear dynamic behavior taking into account the various ground motion intensities, the variability of soil, and SSI. The basic strategy is to train a neural network by a numerical database obtained from a FEM model. This numerical model is further validated by experimental results. An optimum prediction for a nonlinear dynamic response is achieved using Artificial Neural Networks. Finally, fragility curves were established considering SSI for three different soil classes. Results revealed the importance of considering SSI effects on the evaluation of seismic structural damage and risk assessment analysis.
\end{abstract}

Keywords: Fragility curves; Soil-Structure Interaction; ANN; macro-elements.

\section{Introduction}

Earthquakes appear to be one of the most harmful natural disasters. Over the past decades, different regions over the world (Mexico, Italy, China, Algeria...) have been hit by a devastating earthquake. Unfortunately, there is not any reliable way to predict where and when an earthquake will occur. The intensity is still another challenge. In order to establish a quantitative estimate of a seismic risk, the vulnerability analysis should be performed to assess the degree of susceptibility of structural elements to damage. A common form to express the relationship between the damage and the hazard intensity is the fragility curves.

A fragility curve could be established using empirical methods as proposed by [1,2]. Other methods are based on expert opinion, as mentioned in ATC [3] and the guide proposed by [4]. Alternatively, we can use numerical models to obtain the

\footnotetext{
*Corresponding author: Tel.: +213 554928 049. E-mail address: m.i.rachedi@gmail.com.
} 
analytical fragility curves. The analytical fragility curves are established from a statistical determination of the distribution of simulated damage using structural models and varying seismic intensity (usually PGA). These curves usually take into account a limited number of structural properties and use only one single parameter to describe the strong ground motion. In [5], the authors have already proved that a single parameter is not enough to describe the seismic excitation and does not allow expressing the complex relationship between the damages and the parameters characterizing the ground movement. On another side, with the evolution of computer hardware and its use, a new family of computing methods, called soft computing methods, has emerged. These methods are based on heuristic approaches rather than rigorous mathematical approaches. Although at the beginning there was some reluctance towards the use of these heuristic methods, yet its efficiency was revealed later, in many previous cases, to be surprisingly powerful. Currently, their use is continually increasing, especially the most popular neural networks (NN), Metaheuristics and Fuzzy Logic. Soft computing techniques have also been widely used in civil and infrastructure engineering [6-10]. Among soft computing techniques, ANN appears to be a good tool to describe complex relationships influenced by numerous parameters.

In the present paper, the ANN method is used to assess the seismic risk of an existing bridge using the vulnerability curves. ANN needs training data. To establish this database, Non-Linear Time History Analysis is performed to evaluate the dynamic structural response of the bridge. The inelastic time history analysis is performed within the framework of the FEM method using different ground motions characterized by their Peak Ground Acceleration (PGA), Peak Ground Velocity (PGV) and Peak Ground Displacement (PGD) along with Spectrum Intensity (SI), dominant frequency and duration. When dealing with inelastic nonlinear analysis, material non-linearity could be modeled by lumped or distributed (spread) plasticity. Spread plasticity models are based on the use of the classical plasticity approach (or damage approach) with specific constitutive behavior laws [11]. Numerically speaking, within the framework of the finite element method, the non-linearity is spread over integration points (Gauss points). Alternatively, the concept of fibre elements (multi-fibre approach) is considered as a simplified strategy to deal with material non-linearity. In this paper, a multifiber-based model [12] is adopted .

In addition to those nonlinear models, the boundary conditions must be taken into account. Most of the nonlinear dynamic methods do not incorporate the interactions with foundations explicitly. The structure is supposed to be fixed and soil conditions are roughly taken into account via a compatible ground motion. The interaction of the soil with a superstructure has been the subject of numerous investigations. Over the past years, several analytical and experimental studies have been conducted to investigate the effect of Soil-Structure Interaction on the seismic behavior of structures [13] [14]. These studies have indicated that the nonlinear soil-foundation behavior affects the response of the structurefoundation system. Three main approaches are used to model the SSI [15] (i) The classical direct methods based on the 
taken into account. This method is time-consuming especially when the system is geometrically complex with significant nonlinearities in the soil and/or structural materials. (ii) Substructure approach where the SSI problem is decomposed into simpler problems (Kausel's superposition principle: kinematics interaction and inertial interaction). This approach is valid only for linear problems. (iii) Hybrid models that take advantages from the previous ones. Computations are not time-consuming, which is an advantage from an engineering point of view.

The "macro-element" concept considered as a hybrid model is used in the present study. Its ability to simulate the 3D behavior of a viaduct with fixed rigid shallow foundations under static and dynamic loadings has been already proved [16]. Therefore, the input parameters for the ANN are extended to local geotechnical soil characteristics and footing dimensions. Using the results of the numerical simulations, a mapping between the input data (ground motion properties, soil characteristics, footing dimensions) and the dynamic response (study output) is established using an ANN. The predictive power of the ANN is assessed using several examples.

Finally, a log-normal distribution form is used to establish the fragility curves. The log-normal law needs only two parameters (mean and standard deviation) to identify those curves. A limit state criterion is defined as the value of the structural demand that a system is unable to achieve at a specified damage level (or failure level). The state of damage can be specified via limits for any response parameter such as stresses, deformations, displacements, accelerations. The characterization of the damage state, based on these corresponding parameters, depends on the type of the structure and on the structural materials.

\section{Multilayered feed-forward neural networks}

These elements, known as artificial neurons, are brain anatomy inspired. They are deliberately designed to mimic the organizational principles of a biological neuron, such as learning from experience, generalizing from a set of measured data to new cases with different data and summarizing essential characteristics from sets of inputs containing irrelevant data. These neural networks are used to establish relationships (mappings) between a vector of input variables $\mathrm{X}$ and a vector of output variable $\mathrm{Y}$, within the domain of the training data set [17]. ANN-based models have been used earlier to solve civil engineering problems. In 1992, Wu et al. published the first article using ANN to predict structural damages [18]. Recently, Artificial Neural Network (ANN) models have been widely applied to various relevant civil engineering problems. A useful review of ANN used in civil engineering is presented in [19].

An artificial neural network consists of an input layer X, one or more hidden layers (HLs), and an output layer (OL). The neural networks establish the relationship between the input and output by the assignment of weight coefficients to the connections between neurons in two neighbouring layers. These weight coefficients constitute the network weight matrix 
denoted by "Wn", where "n" represents the number of layers associated with weight coefficient matrices. Fig. 1 shows a neural network with three layers (input, hidden and output). Each hidden layer comprises three nodes (neurons).

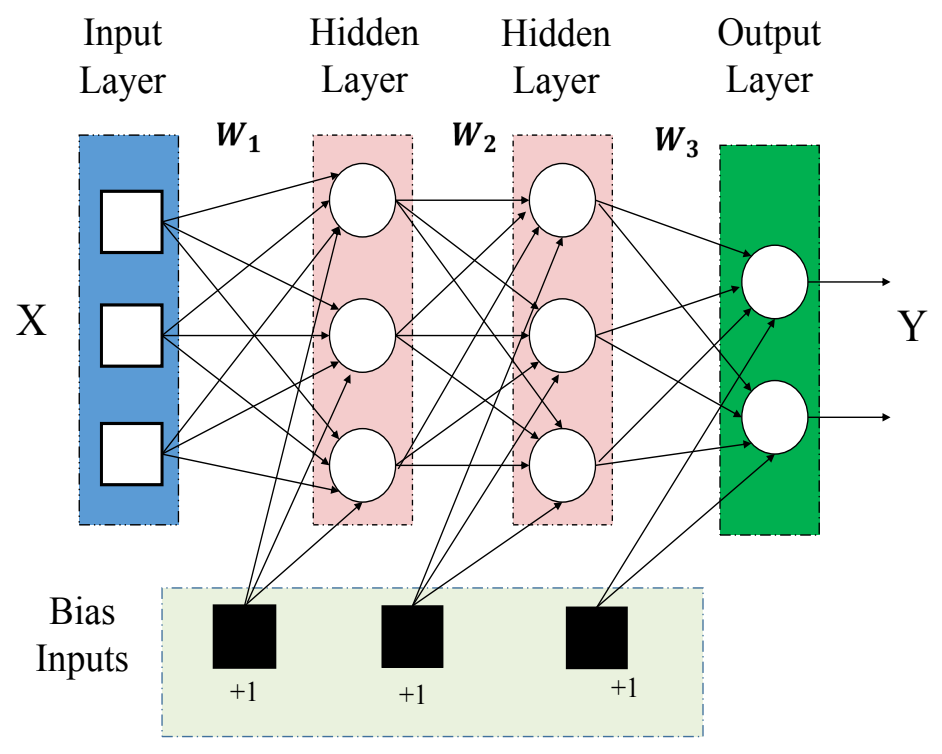

Fig. 1 Double hidden layer BP ANN structure.

Regarding the network architecture, the multilayered feed-forward neural network arrangement, using nonlinear activation functions are currently the most commonly used neural network in engineering applications. In most cases, it enhances the ability of the ANN to "learn" a complex relationship between input and output data set. Each neuron layer receives, as an input, a weighted sum from the previous neighbour layer.

$$
u=v^{T} Z
$$

"T" denotes transposition. The input and weight vectors at each hidden layer have been denoted by $v$ and $z$, and they are different from the precedent $\mathrm{X}$ and $\mathrm{W}$, which are for the input layer and the whole weight network. The output of the neural network is obtained from the last hidden layer using an activation function such as the sigmoid function:

$$
y=f(u)
$$

The aim of training a multilayered feed-forward neural network is to minimize the total error between predicted and output data. The following formula can define the total error:

$$
E(w)=\frac{1}{2} e(w)^{T} e(w)
$$

$\mathrm{e}(\mathrm{w})$ is the error between the target values and the network outputs.

Initially, the weights are used to propagate the learning forward from input to the output layers. However, we can also use the weights to propagate the error backwards from the output back into the network. During learning process, the error 
calculated is propagated back through the layers of the neuronal network by updating the weight coefficients. The process of distributing the calculated error at the output, backward into the network to refine the weights, is called BackPropagation (BP). The new weights are computed iteratively using the following formula:

$$
\mathrm{w}_{\mathrm{k}+1}=\mathrm{w}_{\mathrm{k}}-\left[\mathrm{J}^{\mathrm{T}}\left(\mathrm{w}_{\mathrm{k}}\right) J\left(\mathrm{w}_{\mathrm{k}}\right)+\lambda_{\mathrm{k}} \mathrm{I}\right]^{-1} \mathrm{~J}^{\mathrm{T}}\left(\mathrm{w}_{\mathrm{k}}\right) \mathrm{e}\left(\mathrm{w}_{\mathrm{k}}\right)
$$

Where subscript $\mathrm{k}$ denotes the iteration step, $\lambda_{\mathrm{k}}$ is a scalar that controls convergence properties, and $\mathrm{J}$ is the Jacobian matrix. Many factors such as the complexity of the underlying process represented in the training data set, the network architecture and the training process can influence the total errors between predicted and outputs data. It is important to note that it is not preferable to reduce this error too much. Precisely, reducing network errors to zero risks losing its generalization capabilities [20], and finally, the neuron network would function as an interpolation function.

In the present study, our strategy is to train BP networks using the Bayesian Regularization algorithm associated with an early-stopping criterion on validation data. The early-stopping criterion used is based on the reduction of mean squared error (MSE) for a validation data set. Indeed, excellent results were obtained by stopping the network training when the reduction of MSE between training iterations become marginal, thus preventing the network from over-fitting training data.

\section{Description of the bridge structure and the numerical modeling approach}

A numerical model of a 1: 2.5 scaled viaduct (shown in Fig. 2), which was tested pseudo-dynamically in ELSA (JRC Ispra [21], is performed with FEDEASLab [22]. Fig. 2 illustrates the shape sections of piers and the deck. The three reinforced concrete piers of the bridge have a hollow rectangular section shape, whereas the deck is made of prestressed concrete and presents a hollow 'voussoirs' shape. The (1:2.5) scale model has been tested pseudo-dynamically using the sub-structuring technique in which the piers are physically tested and the deck, assumed to behave elastically, is integrated numerically on-line [21]. 
a)

$80(4 \times 20)$

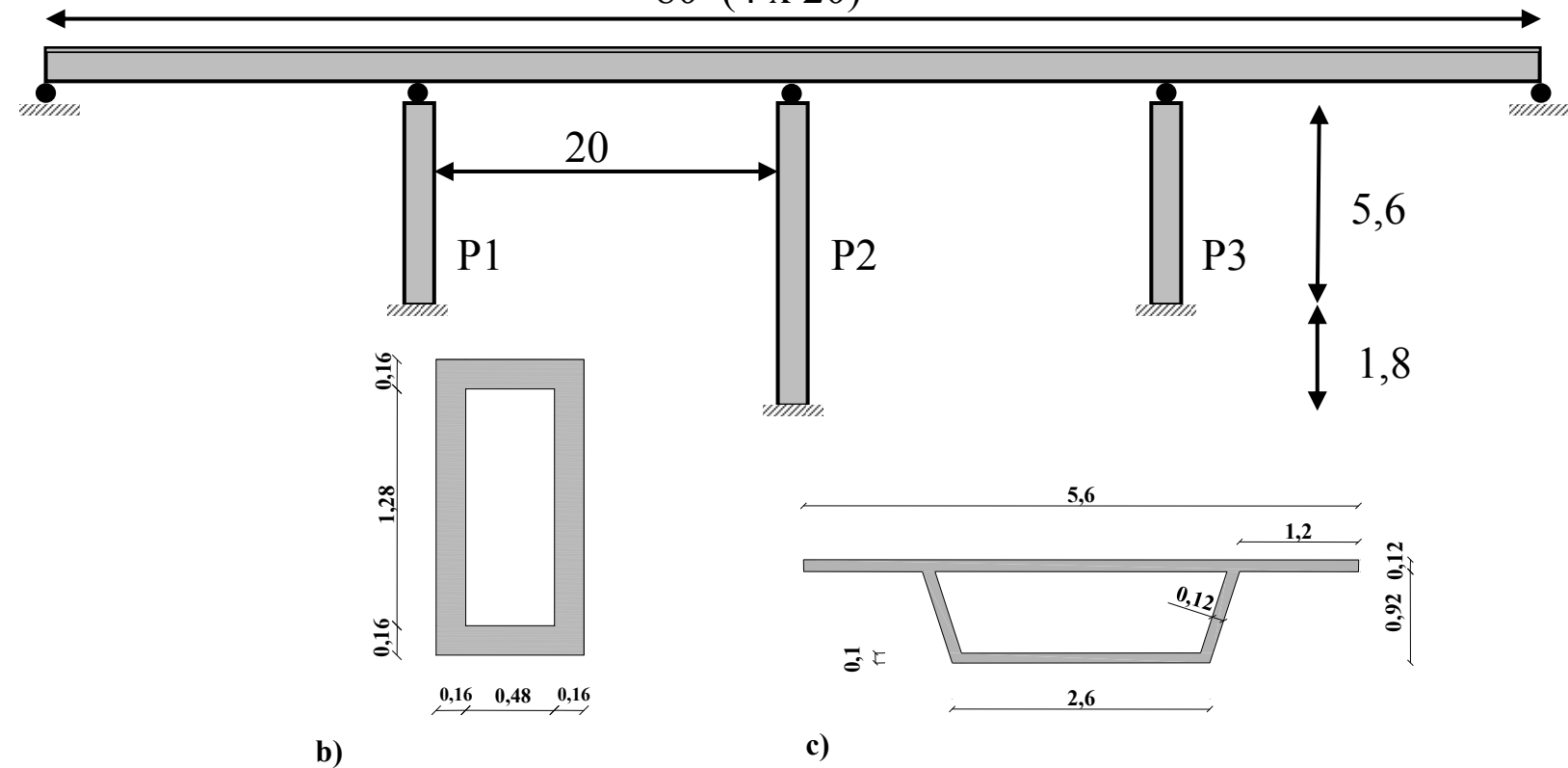

Fig. 2 Viaduct: plan view of the tested viaduct in Ispra, a) 1:2.5 Scaled R/C bridge: plan view of the tested R/C Bridge ELSA, Ispra, Italy [21]. (b) Scheme of the piers, (c) Scheme of the deck (dimensions in meters)

\subsection{Finite Element Model}

The multifiber modelling strategy is adopted to perform the numerical simulations. In a multifiber beam element (Euler Bernoulli or Timoshenko), the section is discretized with steel fibers and concrete fibers. Each fiber is assigned with a uniaxial material constitutive law (Fig. 3).

Piers are modeled with non-linear Timoshenko multifiber beam elements. The piers $\mathrm{P} 1$ and $\mathrm{P} 3$ are discretized into six elements while nine elements are used for the pier P2 (Fig. 4). The mesh is refined at the base of the piers where damage is expected to occur. Details of the fibers used in the section for the piers P1-P3 and P2 are given in Fig. 4. The behavior of the prestressed concrete deck is assumed linear elastic and is discretized using linear beam elements. All sections of piers are modeled with fibers. We use forty fibers for concrete, while one steel fiber is used for each reinforcement bar. As illustrated in Fig. 4, a lumped mass model is adopted. The details of the rotational masses and inertia are given in Table 1. The piers ends are supposed to be fixed. The numerical model is firstly validated without SSI. The numerical results are compared with those given by the experimental tests. The SSI effect will be discussed later. 
Table 1 Masses and rotational inertia.

\begin{tabular}{lcccc}
\hline & $\mathrm{M}_{\mathrm{A}}$ & $\mathrm{M}_{\mathrm{B}}$ & $\mathrm{M}_{\mathrm{C}}$ & $\mathrm{M}_{\mathrm{D}}$ \\
\hline Mass $(\mathrm{Kg})$ & 27,5 & 32 & 34 & 13,75 \\
\hline Rotational inertia $\mathrm{I}_{\mathrm{x}}\left(\mathrm{Kg} \cdot \mathrm{m}^{2}\right)$ & 285 & 287 & 288 & 143 \\
\hline Rotational inertia $\mathrm{I}_{\mathrm{z}}\left(\mathrm{Kg} \cdot \mathrm{m}^{2}\right)$ & 234 & 271 & 271 & 117 \\
\hline
\end{tabular}

(a)

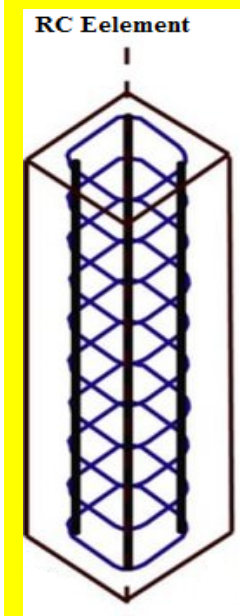

(b)

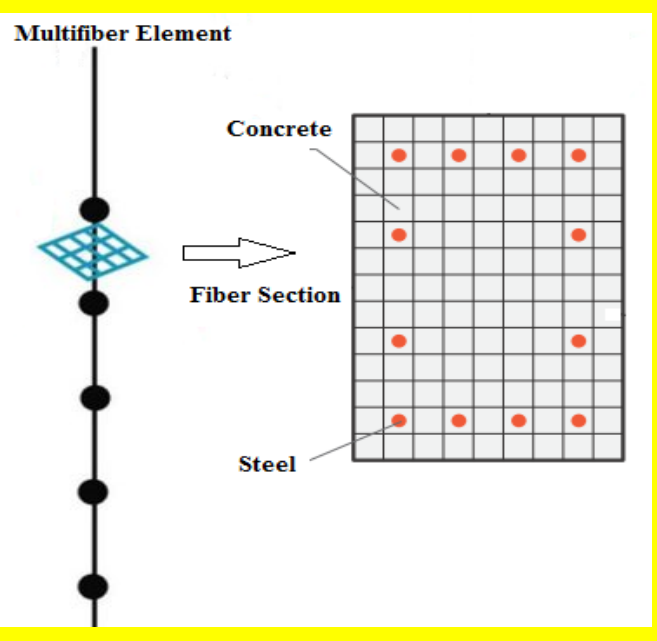

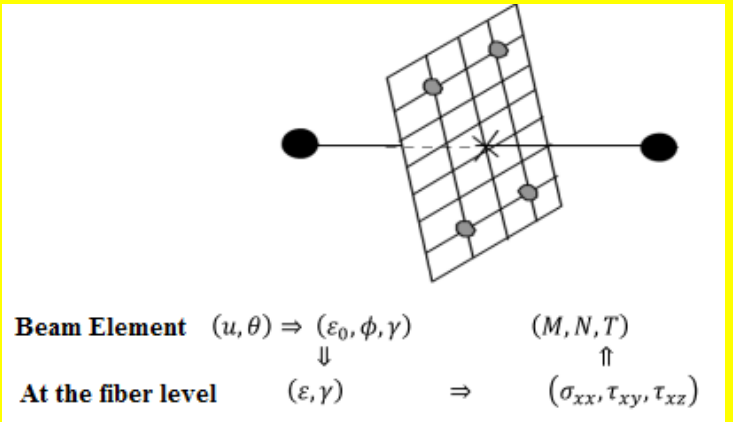

Fig. 3 a) Multifiber beam element principle b) Kinematic and static variables 
a)

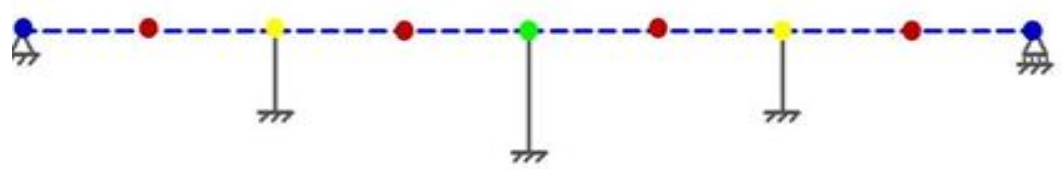

$\mathrm{M}_{\mathrm{A}} \odot \mathrm{M}_{\mathrm{B}} \bigcirc \quad \mathrm{M}_{\mathrm{C}} \odot \quad \mathrm{M}_{\mathrm{D}}$

---linear beam elements — —non-linear Timoshenko multifibre beam

b)

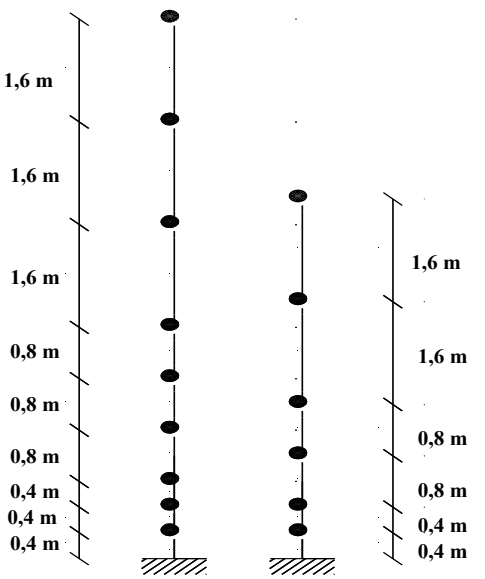

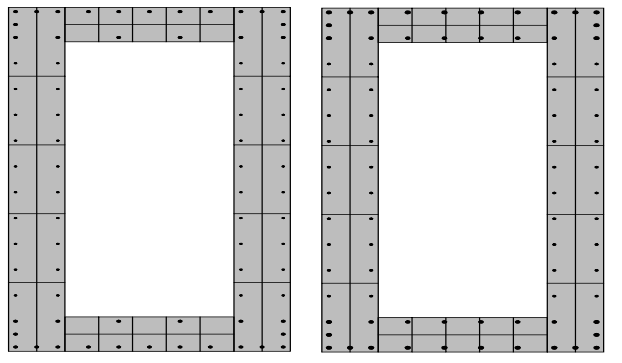

Fig. 4 Multifiber model of the tested RC bridge a) Schematic representation of the numerical model, (b)Multifiber elements and mulifiber cross section for each pier type.

\subsection{Nonlinear behavior laws}

Fig. 5 shows the stress-strain relationships of the constitutive models for concrete and steel. The uniaxial concrete damage law developed by La Borderie [23] is used to reproduce the concrete behavior while the Menegoto and Pinto model [24] is used to reproduce the non linear behavior of steel. Table 2 summarizes the different parameters for both models.
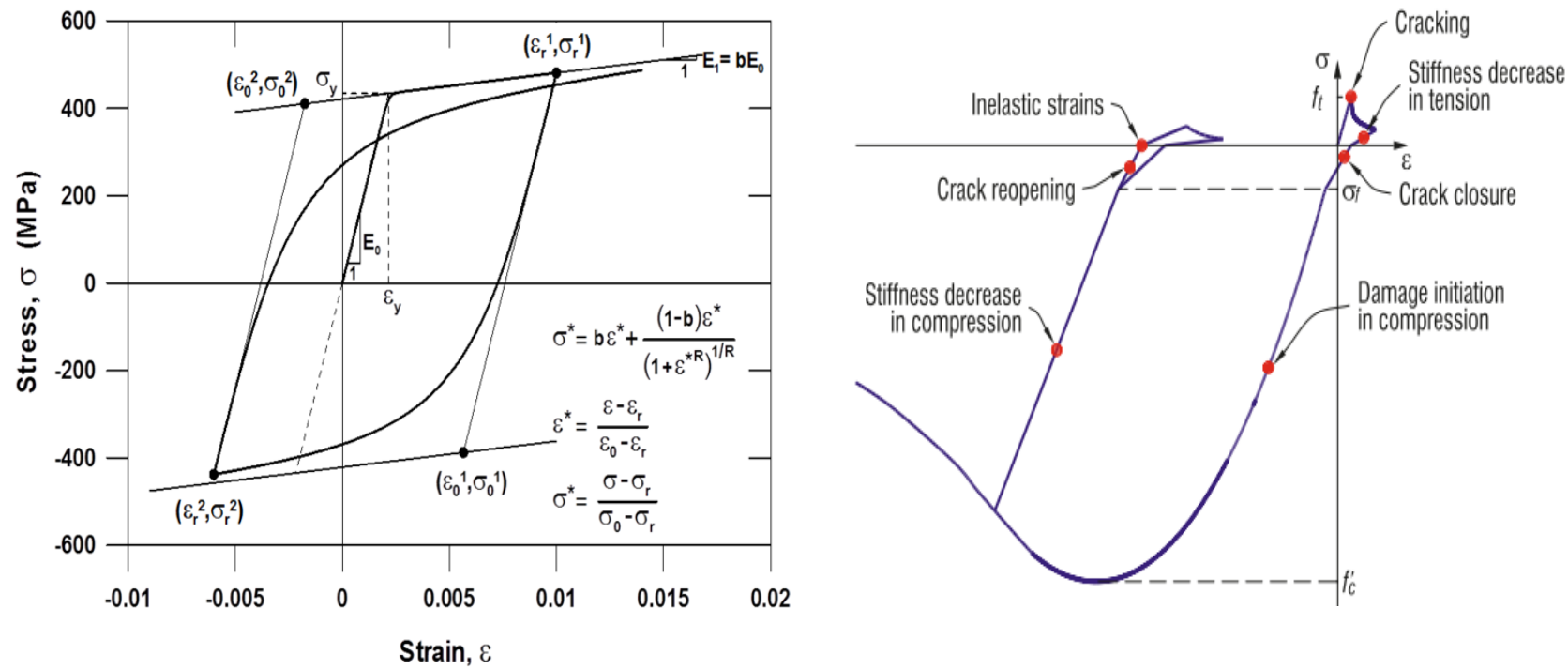

Fig. 5 Concrete and steel constitutive laws (Left) Uniaxial stress-strain relationship of Menegoto and Pinto model [24], (Right) Uniaxial stress-strain response of La Borderie model [23] 
Table 2 Material parameters for concrete and steel constitutive laws.

\begin{tabular}{cccc|cc}
\hline \multicolumn{3}{c|}{ Concrete Parameters } & \multicolumn{2}{c}{ Steel Parameters } \\
\hline$E$ & $29.4 \mathrm{GPa}$ & $B_{1}$ & 1.0 & $E$ & $200 \mathrm{GPa}$ \\
$v$ & 0.175 & $B_{2}$ & 1.3 & $f_{\mathrm{y}}$ & $450 \mathrm{Mpa}$ \\
$Y_{01}$ & $1000 \mathrm{~Pa}$ & $\beta_{1}$ & $0.5 \mathrm{MPa}$ & $f_{\text {su }}$ & $710 \mathrm{Mpa}$ \\
$Y_{02}$ & $0.0001 \mathrm{MPa}$ & $B_{2}$ & $-19 \mathrm{MPa}$ & $\varepsilon_{\text {sh }}$ & 0.0060 \\
$A_{1}$ & $7000 \mathrm{MPa}^{-1}$ & $\sigma_{\mathrm{f}}$ & $3.0 \mathrm{MPa}$ & $\varepsilon_{\text {su }}$ & 0.10 \\
$A_{2}$ & $6.0 \mathrm{MPa}^{-1}$ & & & & \\
\hline
\end{tabular}

\subsection{Model validation}

For the non-linear time history analysis, the same seismic excitation used for the pseudo-dynamic test is used. The latter, represented below in Fig. 6 (b), is a synthetic accelerogram compatible with the 5\% damping design spectrum of EC 8 for soil class B [25], as shown in Fig. 6 (a).

a)

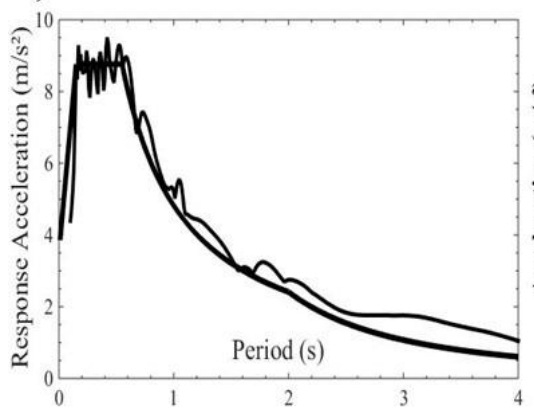

b)

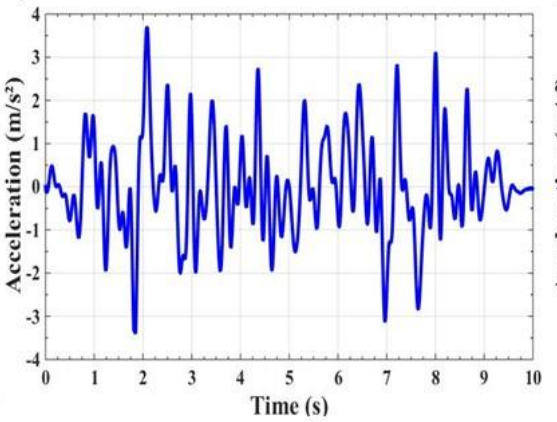

c)

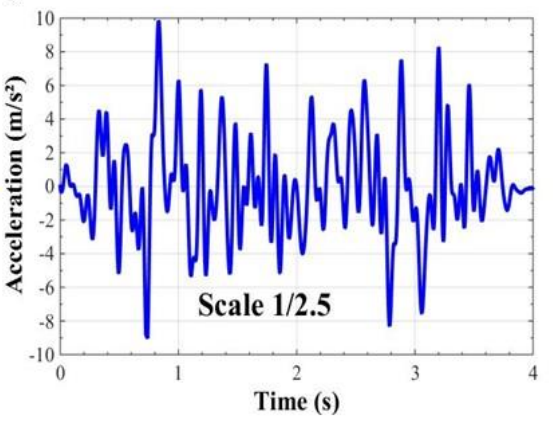

Fig. 6 Synthetic accelerogram compatible with the 5\% damping design spectrum of Eurocode 8 for soil class B, (a) Design Eurocode 8 spectrum for 5\% damping and soil class B, (b) Synthetic accelerogram for the full-scale structure, (c) Synthetic accelerogram for the scaled structure.

In order to respect the similitude laws, the ground motion acceleration will be amplified by an order of 2.5 unlike the time scale which is to be divided by 2.5 (Fig. 6 (c)). Fig. 7 shows a comparison between the numerical structural response and the experimental one. The comparison between modal frequencies obtained from the numerical model and those obtained from experimental tests shows a good agreement (Table 3). However, some disagreements are observed for higher modes. 
Table 3 Numerical and experimental modal frequencies.

\begin{tabular}{c|c|c}
\hline Mode of Vibration & $\begin{array}{c}\text { Numerical } \\
{[\mathrm{Hz}]}\end{array}$ & $\begin{array}{c}\text { Experimental } \\
{[\mathrm{Hz}]}\end{array}$ \\
\hline 1 & 4.2 & 4.2 \\
2 & 6.4 & 6.8 \\
3 & 9.9 & 10.4 \\
4 & 15.8 & 16.8 \\
\hline
\end{tabular}

The time evolution of the transversal top displacements of piers P1, P3, and P2 are well reproduced. The displacement peaks as well as the frequency content of the response shows good agreement with the experimental results.
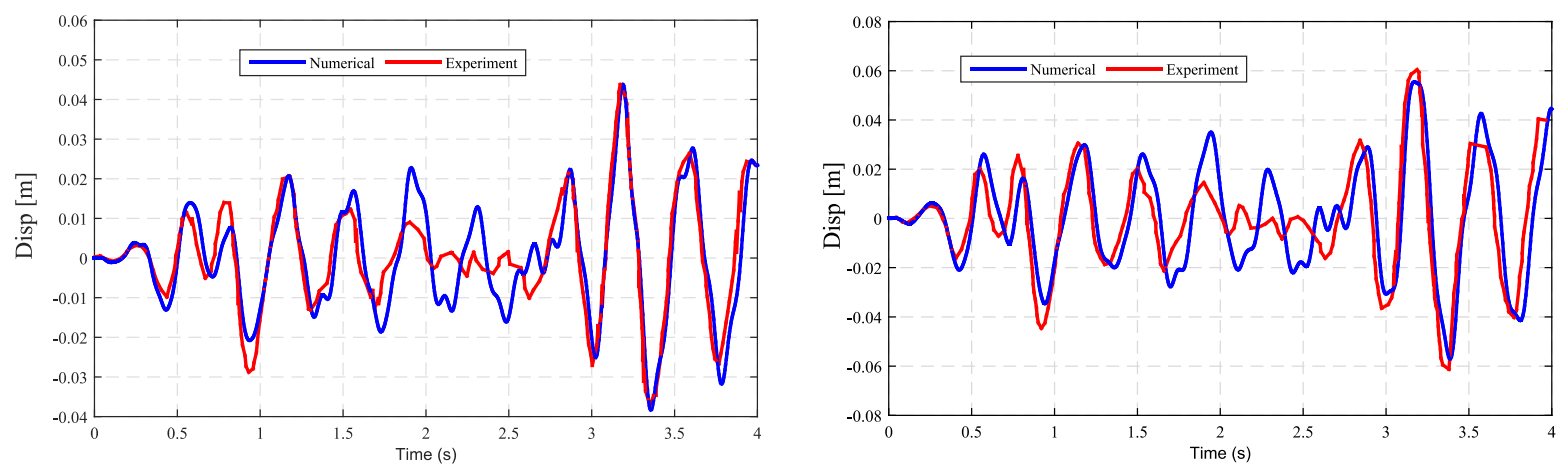

Fig. 7 Experimental (from pseudo-dynamic test [21]) Vs. numerical displacements (Left) Transversal top displacements of piers P1 and P3 (Right) Transversal top displacements of P2.

\section{Influence of the SSI and soil type on the structural response}

As it has been outlined in the introduction, the nonlinear soil-foundation behavior affects the response of the structural system. The interaction of the soil with the viaduct has been introduced by modelling the foundations with the macroelement considering material and geometrical nonlinearities [16].

The macro-element used here, makes possible to model circular, rectangular or strip footing shape lying on a semi infinite soil. The soil structure interaction is taken into account by considering the material non-linearities (soil plasticity) and geometric non-linearities (uplift mechanism) under static and dynamic loadings. The behavior law is written in terms of generalized variables (forces/moments Vs. displacements/rotations) (see Fig. 8 (a)). Non-linearities are supposed to be condensed in a representative point: the centre of the foundation. Material nonlinearities are treated through the classical theories of plasticity. The plastic kinematic variables are computed from a loading surface expressed in terms of generalized variables using the normality rule. Isotropic and kinematic hardenings are taken into account. 
Regarding the geometric non-linearity, the uplift phenomenon is represented by a unique state variable describing the proportion of the surface of the uplifted footing $\delta$ (Fig. 8 (b)). The plasticity theory is also chosen to describe the uplift mechanism. The flow rule is found through geometrical considerations, assuming that the centre of rotation of the foundation always stays in the middle of the non-uplifted segment. The mathematical description is detailed in [26]. Coupling of the different mechanisms is straight forward following the theory of multi-mechanisms [27,28]

a)

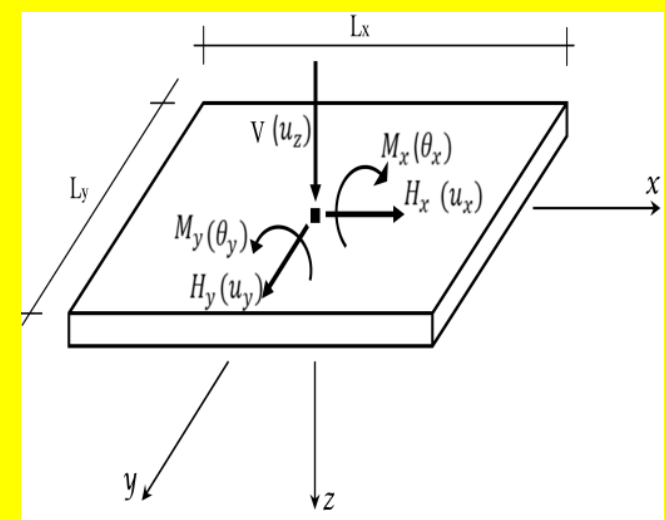

b)

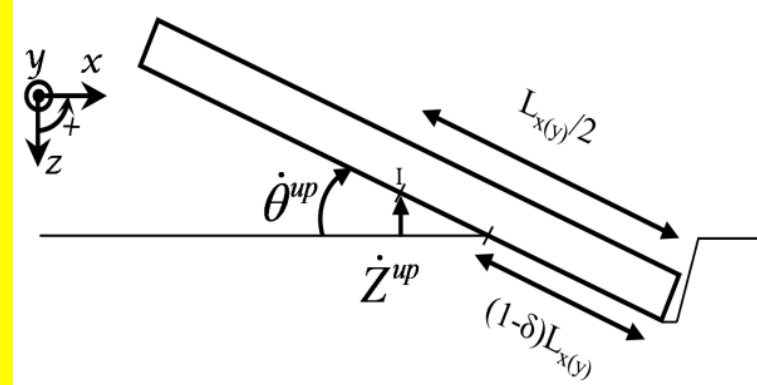

Fig. 8 (a) Generalized variables (forces and displacements) (b) Kinematics of a foundation for the uplift mechanism. (adapted from [27])

In order to amplify the SSI influence, the dimension of the foundation was reduced from $\mathrm{L}=4.2 \mathrm{~m}$ and $\mathrm{B}=2.1 \mathrm{~m}$ to $\mathrm{L}=3.2$ and $\mathrm{B}=1.6 \mathrm{~m}$.

a)

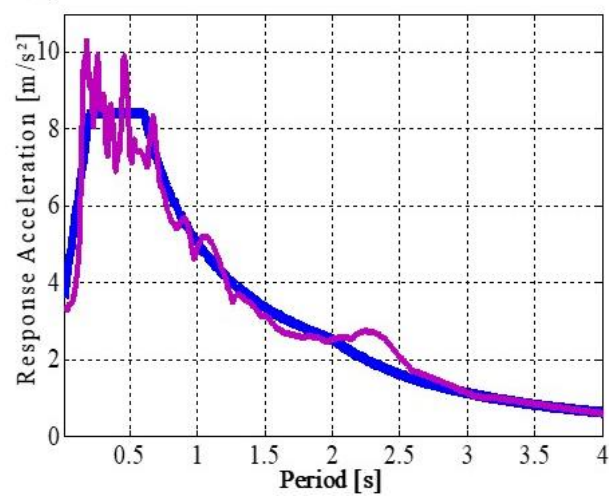

b)

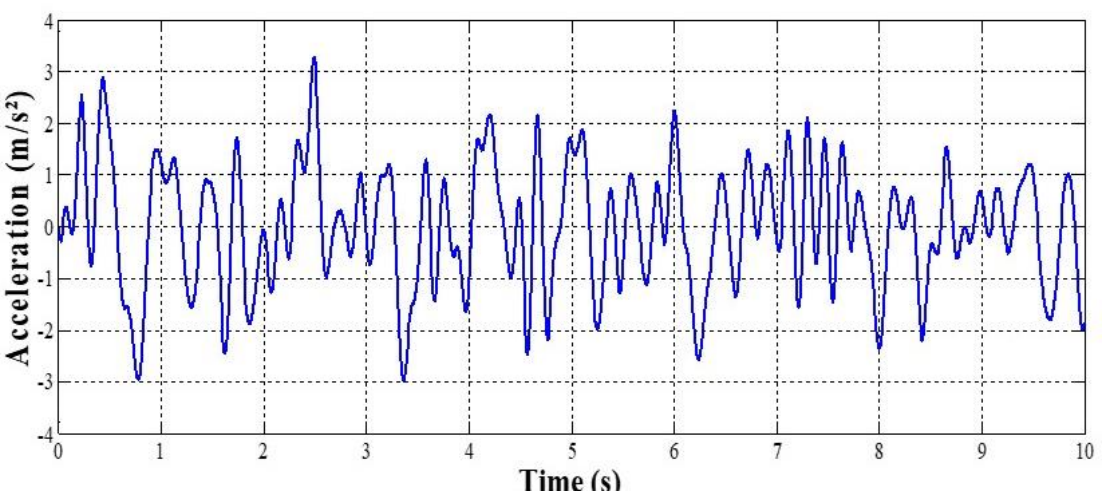

Fig. 9: Artificial generation of synthetic accelerogram corresponding to soil class C, (a) EC8 design spectra (soil class C) for a 5\% damping and synthetic accelerogram spectra, (b) synthetic accelerogram.

On the other hand, in the present section, the quantification of the influence of soil types on the non-linear response of the viaduct model piers is assessed. For this purpose, the nonlinear structural response of the viaduct is performed for two soil types (class B and class C). Previously, a seismic signal compatible with the response spectrum for a soil class B was used. 
Now, for soil class $\mathrm{C}$, in order to avoid the ground motion parameters' effects on the non-linear dynamic response and to keep the same frequency content of the seismic signal, we will artificially generate a second accelerogram for soil class C from the first synthetic accelerogram (class B). The response spectrum of the generated accelerogram should be compatible with the EC8 computing spectrum for the soil class C (see Fig. 9). The second accelerogram is generated using the conditional generation approach of seismic signals compatible with a target response spectrum. This approach implemented in the free software developed by M. Rachedi [29] makes it possible to preserve the frequency content of the original signal while guaranteeing PGAs compatible with the soil profile.

The generated signal is represented in Fig. 9(b). A comparison between the response spectrum and that of EC8 (Soil type C) is given in Fig. 9(a). Otherwise, in Fig. 10, a comparison is made between the artificial accelerograms for the two soil types. The PGA for the new artificial seismic signal is $0.30 \mathrm{~g}$, a value little smaller than that of the original one.

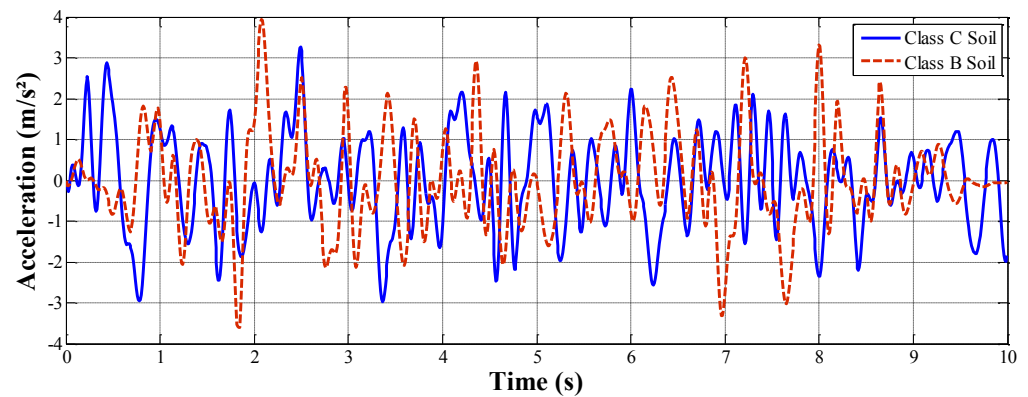

Fig. 10 Comparison between synthetic accelerograms compatible with $\mathrm{B}$ and $\mathrm{C}$ soil type design response spectrum of EC8

Fig. 11 shows the comparison between the numerical temporal evolutions of the transversal top displacements of piers for two soil classes. Despite the fact that the intensity of the seismic excitation (compatible with soil type C) is slightly lower, the transversal top displacements considering a foundation with a soil class $\mathrm{C}$ are higher than those corresponding to the foundation of a soil class B. Unquestionably, the non-linear dynamic behavior of the viaduct is completely modified when taking into account the interaction between the foundations of the piers with the ground. Briefly, the influence of the SSI must be considered when estimating the risk as it amplifies the displacements and internal forces of the bridge piers. 
a)

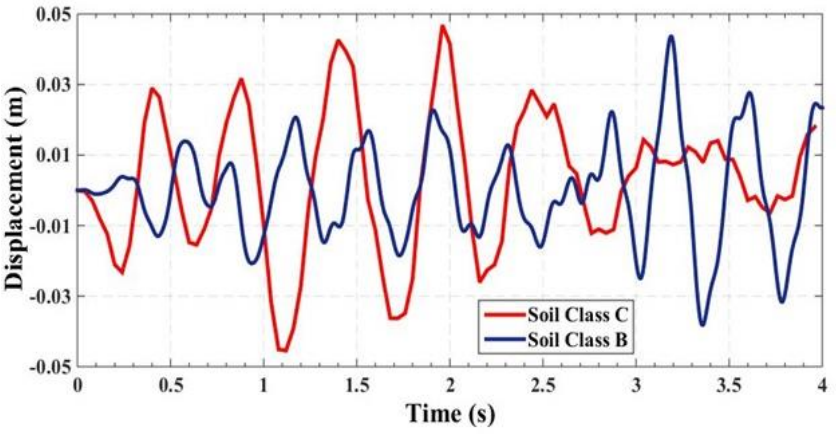

b)

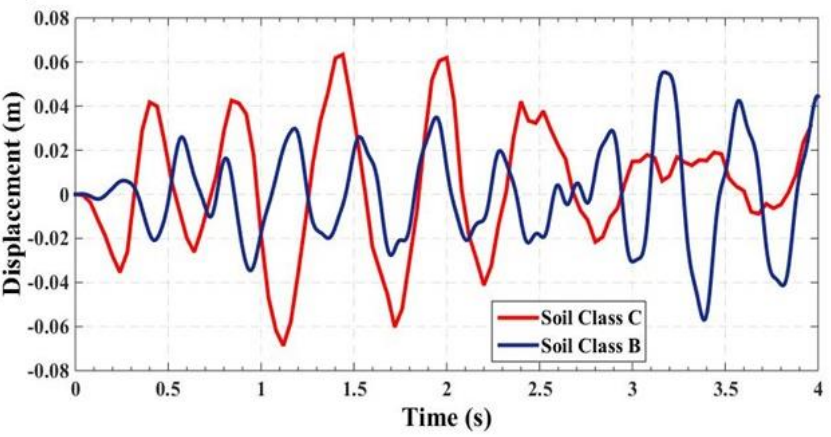

Fig. 11 Comparison of the time evolution of the transversal top displacements of piers (a) P1 and P3, (b) P2

\section{Training and testing of ANN}

\subsection{Soil and ground motion parameters}

In this investigation, a set of twelve parameters were used for artificial neuronal analysis: seven ground motion characteristics, three parameters for soil characteristic (shear modulus, the average shear-wave velocity, and the loadbearing capacity) and the remaining two parameters are related to the footing dimension.

The seven ground motion parameters are:

(i) PGA, Peak Ground Acceleration,

(ii) PGA/PGV, Peak Ground Acceleration by Peak Ground Velocity,

(iii) $\mathbf{S}_{\mathbf{a}_{-} 1}, 5 \%$ critical damping ratio Spectral acceleration at $1.0 \mathrm{~s}$ natural periods.

(iv) $\quad \mathbf{A I}(\%)$, Arias intensity,

(v) DF : Dominant Frequency

(vi) SI Spectral velocity response of a single degree of freedom oscillator with a natural period between $1 \mathrm{~s}$ and $2,5 \mathrm{~s}$ and a damping ratio of $20 \%$ :

(vii) ED: The Effective Duration of the earthquake.

Riddell [30] demonstrates a good correlation between those ground motion characteristics and the inelastic structural response.

Table 4 Earthquakes parameters used in numerical simulations.

\begin{tabular}{lccccccc}
\hline Earthquakes & $\begin{array}{c}\text { PGA } \\
(\mathrm{g})\end{array}$ & $\begin{array}{c}\text { PGV } \\
(\mathrm{cm} / \mathrm{s})\end{array}$ & $\begin{array}{c}\text { AI } \\
(\mathrm{m} / \mathrm{s})\end{array}$ & $\begin{array}{c}\text { Sa_1 } \\
\left(\mathrm{m} / \mathrm{s}^{2}\right)\end{array}$ & $\begin{array}{c}\text { DF } \\
(\mathrm{Hz})\end{array}$ & $\begin{array}{c}\text { ED } \\
(\mathrm{s})\end{array}$ & $\begin{array}{c}\text { SI } \\
(\mathrm{m} / \mathrm{s})\end{array}$ \\
\hline Elcentro (USA 1940) & 0,21 & 48,8 & 1,29 & 2,77 & 2,14 & 24,5 & 0,48 \\
\hline Kaecli (Turquie 1999) & 0,35 & 62,5 & 1,30 & 3,75 & 0,29 & 12,9 & 0,73 \\
\hline Northridge (USA 1994) & 0,57 & 52,0 & 2,77 & 5,18 & 1,25 & 8,9 & 0,76 \\
\hline Loma prieta (USA 1989) & 0,37 & 33,0 & 1,19 & 2,96 & 2,47 & 10,9 & 0,50 \\
\hline Imperial Valey (USA 1979) & 0,31 & 29,7 & 1,70 & 4,79 & 1,46 & 24,1 & 0,53 \\
\hline Boumerdas (Algeria 2003) & 0,55 & 27,5 & 1,84 & 2,29 & 3,30 & 10,6 & 0,45 \\
\hline
\end{tabular}


In order to perform the learning process by $\mathrm{ANN}$, we build the dataset by varying the seismic excitation, the soil class and the foundation dimension. During the FEM analysis, six ground motion accelerations will be scaled to impose seismic excitation with a PGA varying from 0.1 to $1.0 \mathrm{~g}$ while preserving other seismic characteristics such as the frequency content or the duration of the recording. These characteristics are listed in Table 4. Three different soil types (B, C, and D) have been adopted. Table 5 indicates the different parameters of each soil class $\left(\mathrm{G}, \mathrm{V}_{\mathrm{s} 30}\right.$ and $\left.\mathrm{q}_{\max }\right)$. According to EC8, the site should be classified according to the value of the average shear wave velocity $\mathrm{Vs}_{30}$.

Table 5 Soil Class Characteristics

\begin{tabular}{cccc}
\hline & Class B & Class C & Class D \\
\hline $\mathrm{G}(\mathrm{Mpa})$ & 246 & 45 & 19 \\
\hline $\mathrm{Vs}(\mathrm{m} / \mathrm{s})$ & 360 & 180 & 100 \\
\hline $\mathrm{q}_{\max }(\mathrm{Mpa})$ & 4.13 & 1.43 & 0.400 \\
\hline
\end{tabular}

\subsection{Assessment of the predictive power of ANNs}

From the transient nonlinear analysis performed above, a dataset was obtained with a structural response. This dataset was randomly divided into $80 \%$ for training, $10 \%$ for testing and $10 \%$ for validation. The configuration of all neural networks depends a lot on the selection of initial weights. That's why several ANNs with different numbers of HL neurons were investigated. Fifty networks were trained, varying the amount of HL neurons in order to find the optimum configuration.

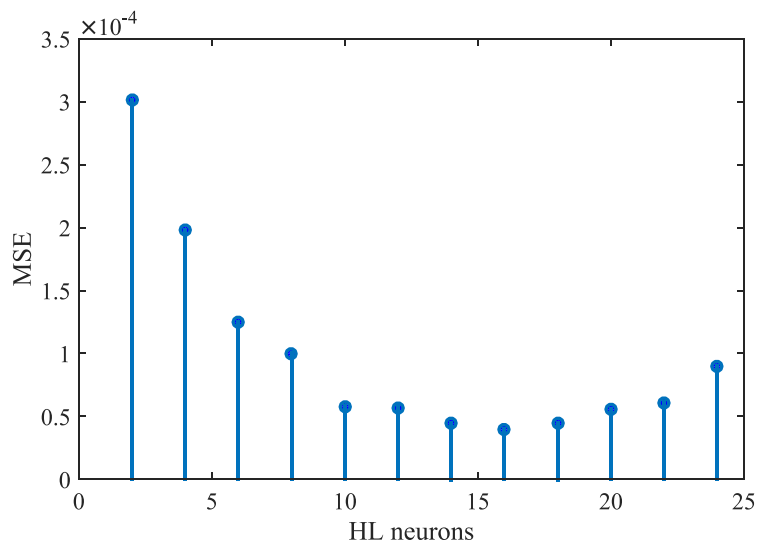

(a)

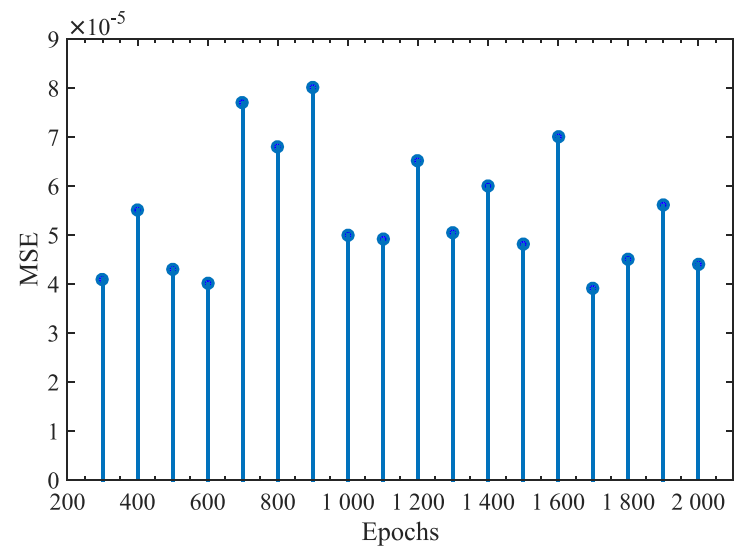

(b)

Fig. 12 MSE produced by trained ANNs, (a) MSE produced by trained ANNs against the different numbers of HL neurons, (b) MSE provided by 16 HLs ANN against the different number of epochs. 
The mean squared error (MES) is chosen to evaluate the performance of the ANN training. The measured MSE of the trained neural network gives an idea about the network performance, especially after the application of data to other untrained cases. The lowest MSE obtained for each of the 50 trained networks is shown in (Fig. 12 (a)). We can note the excellent performance over a range of all ANN configurations. However, the network with 16 HL neurons offers the smallest MSE error. Another prospecting is conducted for the adopted network. Indeed, we need to determine the optimal number of the epoch during neural network training. Therefore, we build several networks by varying the number of epochs, and the MSE is measured for each trained network for the sake of determining the optimal period. By plotting MSE against the number of epochs (Fig. 12 (b)), we can notice that the higher number of epochs is not necessarily the best choice. Fig. 12 (b) showed clearly that 600 epochs can be enough to obtain the lowest MSE.
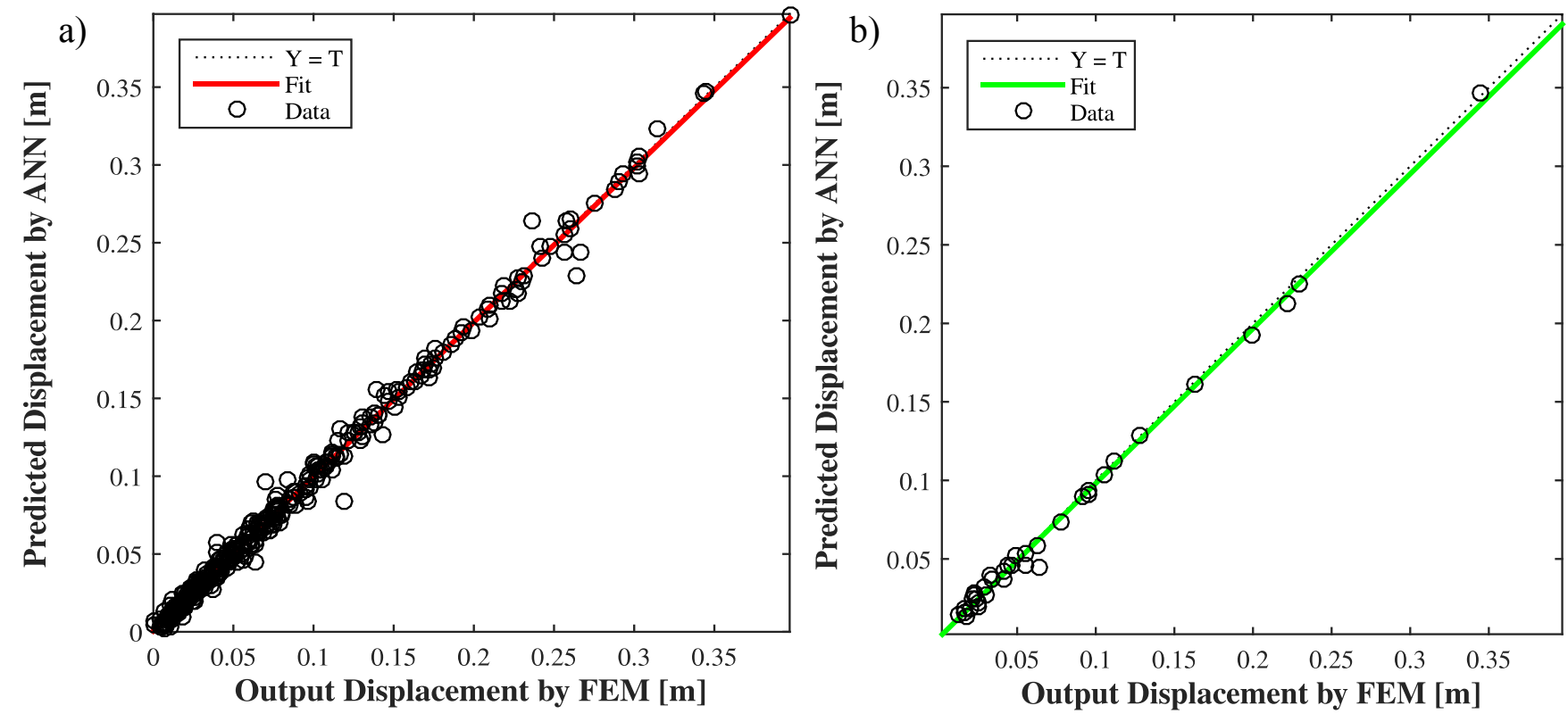

Fig. 13 FEM output displacements vs. ANN predicted displacements (a) all data set $\mathrm{R}=0.99$, (b) test data set $\mathrm{R}=0.99$

In order to assess the predictive power of the $\mathrm{ANN}$, the predicted response by $\mathrm{ANN}$ would be equal to the value obtained from FEM analysis. The plot in Fig. 13 gives the transversal top displacements of pier 2 (the critical one) obtained from FEM analysis vs. the ANN predicted ones for the testing data and all data. Most of the results sit on the straight diagonal reference line showing a highly predictive power of the trained ANN possesses.

\subsection{Assessment of generalization capabilities of ANNs}

In order to assess the generalization capability of our trained ANN, the displacement response of the bridge (transversal top displacements of pier 2) for both unseen soil characteristics and unseen foundation dimensions are predicted. 
Concerning seismic excitation, the characteristics of the previous earthquake events, already used during learning, have been used. Fig. 14 shows the predicted displacement from ANN vs. FEM-based value. Obviously, the results show that the ANN is able to predict the structural response for generalized cases (unseen soil characteristics ....).

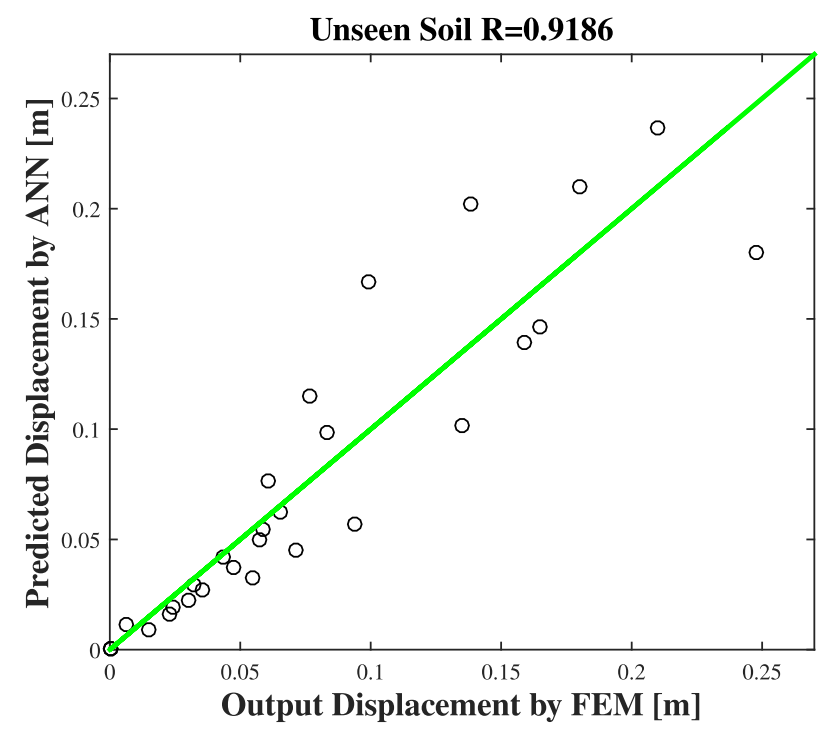

Fig. 14 Comparison of unseen displacement responses predicted by FEM and ANN.

\section{FRAGILITY CURVES}

As mentioned in the introduction, the objective of the present paper is to establish fragility curves of the bridge described above. The Monte Carlo simulation method is considered as the most efficient analytical method to establish "exact" fragility curves, yet a large number of simulations are still required [1]. In this case, the seismic fragility of a structure is defined as the conditional probability of failure for a corresponding intensity of ground motion. The evaluation of the probability of failure for each level of the ground motion intensity allows obtaining, at the end of the process, all the points of the fragility curve Fr (a) defined by the following equation:

$$
F_{r}(a)=P[G(Z) \leq 0 \mid A=\alpha] \cong \frac{\sum 1[G(Z) \leq 0 \mid A=\alpha]}{N_{S a}}
$$

The indicator function $1[\ldots]$ is a function which is equal to 1 if there is a failure, 0 otherwise. Therefore, $\sum 1[G(Z) \leq$ $0 \mid A=a]$ is actually the number of intensity earthquakes causing failure. $\mathrm{N}_{\mathrm{sa}}$ is the number of ground motion used with the same seismic intensity PGA equal to "a." Consequently, the quality of the approximation done by the Monte Carlo simulation method is so much more improved as the number of ground motion is higher.

Equation 6 describes the log-normal cumulative law model, a statistical model frequently used to represent fragility curves. In this model, the probability of exceeding a state of damage or failure is defined by two parameters of the cumulative probability function $(\mathrm{Am}, \beta)$ : 


$$
F_{r}(a)=\Phi\left[\frac{\ln \left(\frac{a}{A_{m}}\right)}{\beta}\right]
$$

Where $\Phi$ is the probability distribution function of the reduced normal centred law, $A_{m}$ is the median and $\beta$ is the standard deviation of the natural logarithm of the seismic intensity A.

Table 6 Structural damage category definition.

\begin{tabular}{ccc}
\hline Structural Performance Levels & Damage States & Damage Index (Drift) \\
\hline $\begin{array}{c}\text { Collapse Prevention } \\
(\mathrm{CP})\end{array}$ & Extensive cracking & $4 \%$ \\
\hline $\begin{array}{c}\text { Life Safety } \\
(\text { LF })\end{array}$ & Extensive damage & $2 \%$ \\
\hline $\begin{array}{c}\text { Immediate Occupancy } \\
(\text { IO) }\end{array}$ & Minor hairline cracking & $1 \%$ \\
\hline $\begin{array}{c}\text { Fully Operational } \\
\text { (FO) }\end{array}$ & No damage & $<0,5 \%$ \\
\hline
\end{tabular}

Finally, data are fitted using a log-normal cumulative distribution function and the fragility curves are established for our studied case for various damage states according to Table 6 [31]. Fig. 15 depicts the comparative plots of fragility curves derived as a function of PGA for SSI models considering three scenarios of foundation soil class (B, C and D). A significant increase in fragility is observed for the SSI models founded on soft soils (D) compared with other soils (B and C). That could be attributed to the amplification due to SSI effect. Thus, higher drift demands increase fragility estimates.

For a PGA value around 1g, the initial probability of the life safety (LF) limit states increased from $30 \%$ considering soil B condition to $90 \%$ for soil of class D. In addition, the model considering soil class B or C never achieved the complete damage state for the maximum intensity $(\mathrm{PGA}=1 \mathrm{~g})$, while the model with SSI considering soil class D does accomplish this state. Thus, the soil properties and SSI may play a crucial role in the expected structural damage, as it is expressed in terms of the maximum drift ratio, and therefore they should not be neglected for seismic risk assessment. 
a)
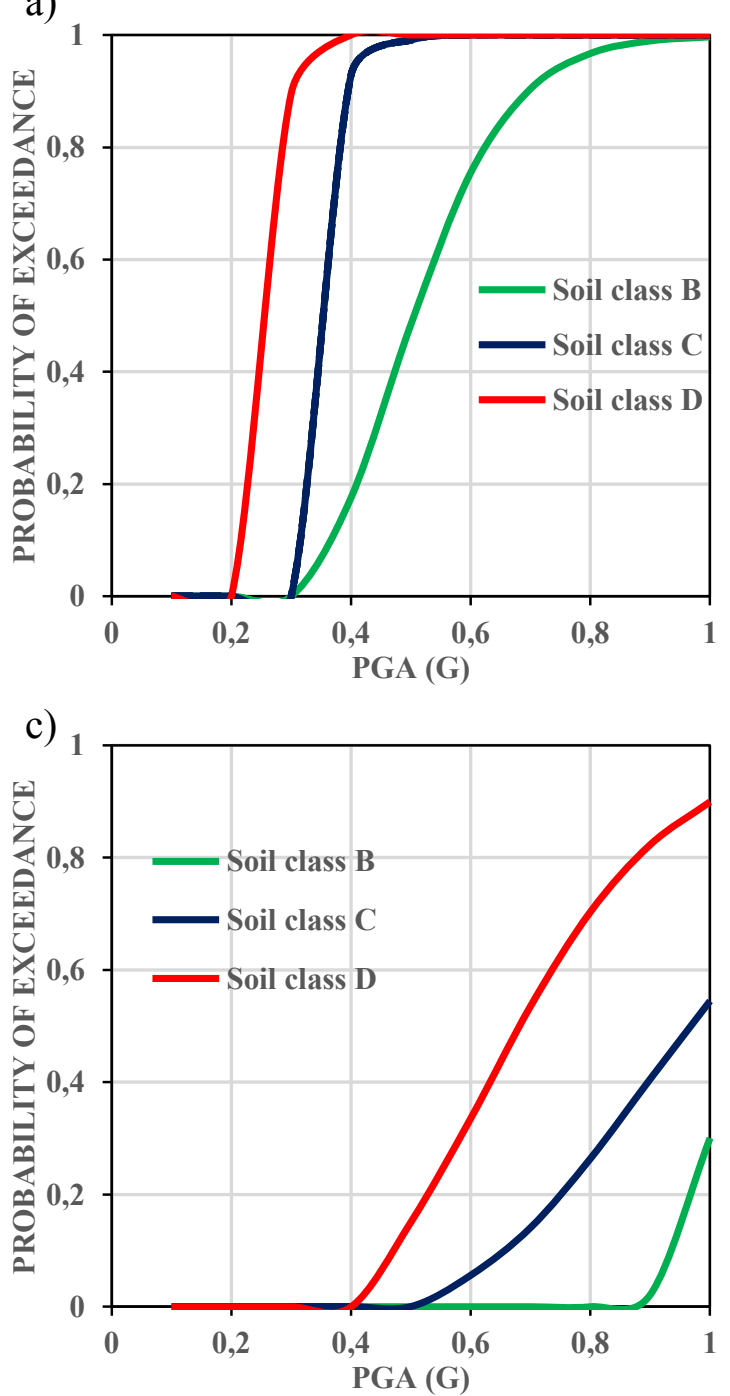

b)

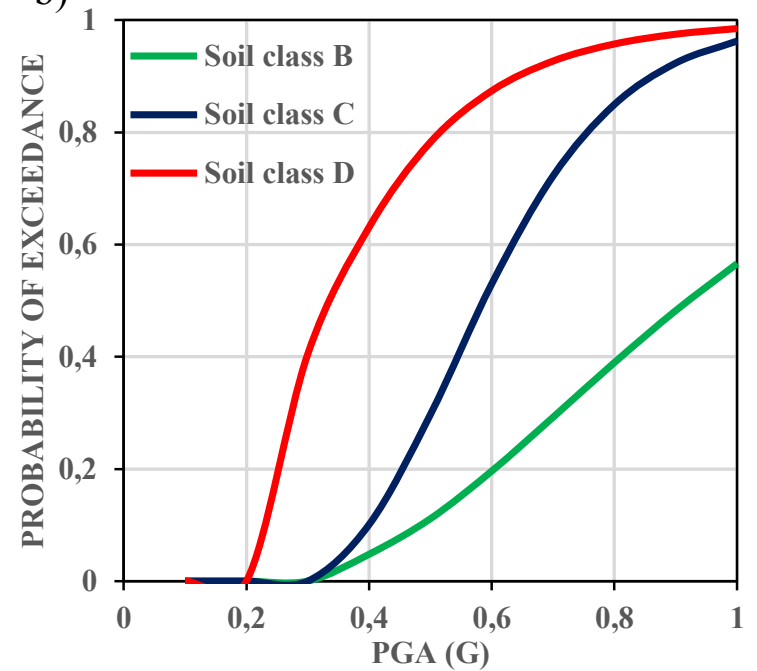

d)

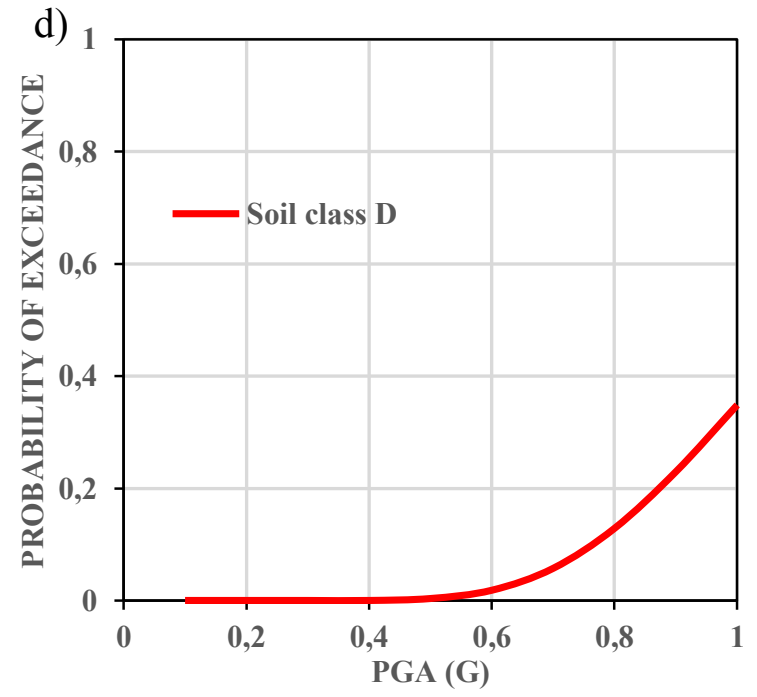

Fig. 15 Fragility curves (a) Fully Operational (FO), (b) Immediate Occupancy (IO), (c) Life Safety (LF), d) Collapse Prevention (CP)

\section{Conclusions}

The computational effort involved in Monte Carlo simulation-based methodology for obtaining fragility curves considering numerous parameters is excessive and time-consuming. This paper proposed an application of Neural Networks to assess the seismic risk of a viaduct (pseudo-dynamically tested in ELSA (JRC Ispra)) considering the random variability of three distinct parameters which are seismic intensity levels, Soil-Structure Interaction, and different classes of soil.

The trained Back-Propagation Neural Network is successfully applied to predict the viaduct structural response. The generalization capabilities performance of the ANN was assessed using unseen cases. Finally, based on the ANN predicted results, fragility curves were established for a structural limit state (failure index) considering three classes of soil. It has 
been demonstrated that the use of ANN for the numerical generation of fragility curves could be very effective both in terms of time and accuracy. Across all fragility curves, it was shown that SSI has the potential to severely increase the exceedance probability of damage states. However, more numerical investigations are needed to explore the performance of the proposed approach for other structural and foundation systems.

\section{Acknowledgements}

The present work has been performed at the RISAM research laboratory (University of Tlemcen). The authors gratefully acknowledge financial support from the DGRSDT. 


\section{References}

[1] Shinozuka M, Kim S-H, Kushiyama S, Yi J-H. Fragility curves of concrete bridges retrofitted by column jacketing. Earthq Eng Eng Vib 2002;1:195-205. https://doi.org/10.1007/s11803-002-0065-2.

[2] Yazgan U. Empirical seismic fragility assessment with explicit modeling of spatial ground motion variability. Eng Struct 2015;100:479-89. https://doi.org/10.1016/j.engstruct.2015.06.027.

[3] ATC. Earthquake Damage Evaluation Data for California, Report No. ATC-13. Redwood City, CA: 1985.

[4] Wakefield D, Ravindra M, Merz K, Hardy J. Seismic Probabilistic Risk Assessment Implementation Guide. Final Report 1002989, EPRI; 2003.

[5] Kwon O-S, Elnashai A. The effect of material and ground motion uncertainty on the seismic vulnerability curves of RC structure. Eng Struct 2006;28:289-303. https://doi.org/10.1016/j.engstruct.2005.07.010.

[6] Lautour ORD, Omenzetter P. Prediction of seismic-induced structural damage using artificial neural networks. Eng Struct 2009;31:600-6. https://doi.org/10.1016/j.engstruct.2008.11.010.

[7] Arangio S, Bontempi F. Soft Computing Based Multilevel Strategy for Bridge Integrity Monitoring: Multilevel strategy for bridge integrity monitoring. Comput-Aided Civ Infrastruct Eng 2010;25:348-62. https://doi.org/10.1111/j.1467-8667.2009.00644.x.

[8] Arangio S, Bontempi F. Structural health monitoring of a cable-stayed bridge with Bayesian neural networks. Struct Infrastruct Eng 2015;11:575-87. https://doi.org/10.1080/15732479.2014.951867.

[9] Sobhani J, Ramezanianpour AA. Service life of the reinforced concrete bridge deck in corrosive environments: A soft computing system. Appl Soft Comput 2011;11:3333-46. https://doi.org/10.1016/j.asoc.2011.01.004.

[10] Falcone R, Lima C, Martinelli E. Soft computing techniques in structural and earthquake engineering: a literature review. Eng Struct 2020;207:110269. https://doi.org/10.1016/j.engstruct.2020.110269.

[11] Matallah M, La Borderie C. Inelasticity-damage-based model for numerical modeling of concrete cracking. Eng Fract Mech 2009;76:1087-108. https://doi.org/10.1016/j.engfracmech.2009.01.020.

[12] Kotronis P, Grange S. Simplified modelling strategies for reinforced concrete structures. Eur J Environ Civ Eng 2010;14:823-38. https://doi.org/10.1080/19648189.2010.9693264.

[13] Mylonakis G, Gazetas G. SEISMIC SOIL-STRUCTURE INTERACTION: BENEFICIAL OR DETRIMENTAL? J Earthq Eng 2000;4:277-301. https://doi.org/10.1080/13632460009350372.

[14] FEMA P-750. NEHRP Recommended Seismic Provisions for New Buildings and Other Structures 2009.

[15] Pecker A. Dynamique des sols. Presse, ENPC : Paris, France; 1984.

[16] Grange S, Botrugno L, Kotronis P, Tamagnini C. The effects of Soil-Structure Interaction on a reinforced concrete viaduct. Earthq Eng Struct Dyn 2011;40:93-105. https://doi.org/10.1002/eqe.1034.

[17] Ghaboussi J, Wu X. Soft computing with neural networks for engineering applications: Fundamental issues and adaptive approaches. Struct Eng Mech 1998;6:955-69.

[18] $\mathrm{Wu} \mathrm{X,} \mathrm{Ghaboussi} \mathrm{J,} \mathrm{Garrett} \mathrm{JH.} \mathrm{Use} \mathrm{of} \mathrm{neural} \mathrm{networks} \mathrm{in} \mathrm{detection} \mathrm{of} \mathrm{structural} \mathrm{damage.} \mathrm{Comput} \mathrm{Struct}$ 1992;42:649-59. https://doi.org/10.1016/0045-7949(92)90132-J.

[19] Adeli H. Neural Networks in Civil Engineering: 1989-2000. Comput-Aided Civ Infrastruct Eng 2001;16:126-42. https://doi.org/10.1111/0885-9507.00219.

[20] Pathirage CSN, Li J, Li L, Hao H, Liu W, Ni P. Structural damage identification based on autoencoder neural networks and deep learning. Eng Struct 2018;172:13-28. https://doi.org/10.1016/j.engstruct.2018.05.109.

[21] Pinto A, Verzelleti G, Pegon P, Magonette G, Negro P, Guedes J. Pseudo dynamic testing of large-scale R / C bridges. HMC Grant Holder, Report EUR 16378 EN; 1996.

[22] Filippou F, Constantinides M. FEDEASLab getting started guide and simulation examples. NEESgrid Technical Report; 2004.

[23] La Borderie C. Phénomènes unilatéraux dans un matériau endommageable : Modélisation et application à l'analyse de structures en béton. Ph.D. Thesis. Paris 6, 1991.

[24] Menegotto M, Pinto PE. Method of Analysis for Cyclically Loaded R. C. Plane Frames Including Changes in Geometry and Non-Elastic Behavior of Elements under Combined Normal Force and Bending. Symp. Resist. Ultim. Deform. Struct. Acted Well Defin. Repeated Loads Int. Assoc. Bridge Struct. Eng., Zurich, Switzerland: 1973, p. $15-22$.

[25] Eurocode. BS EN 1998-5:2004 - Eurocode 8: Design of structures for earthquake resistance - Part 5: Foundations, retaining structures and geotechnical aspects. Eurocode 8 2004;5.

[26] Grange S, Kotronis P, Mazars J. A macro-element for a shallow foundation to simulate Soil-Structure Interaction considering uplift. Comptes Rendus Mécanique 2008;336:856-62. https://doi.org/10.1016/j.crme.2008.10.002.

[27] Grange S, Kotronis P, Mazars J. A macro-element to simulate 3D soil-structure interaction considering plasticity and uplift. Int J Solids Struct 2009;46:3651-63. https://doi.org/10.1016/j.ijsolstr.2009.06.015.

[28] Grange S, Kotronis P, Mazars J. A macro-element to simulate dynamic Soil-Structure Interaction. Eng Struct 2009;31:3034-46. https://doi.org/10.1016/j.engstruct.2009.08.007.

[29] Rachedi M, Benmansour N, Djafour M. Génération conditionnelle de signaux sismiques artificiels variables dans l'espace compatibles aux spectres de réponses sans le problème de l'intégrabilité. AFPS, France: 2015.

[30] Riddell R. On Ground Motion Intensity Indices. Earthq Spectra 2007;23:147-73. https://doi.org/10.1193/1.2424748. 
[31] FEMA-356. PRESTANDARD AND COMMENTARY FOR THE SEISMIC REHABILITATION OF BUILDINGS 2000. 